\title{
Air pollution and the elderly: oxidant/antioxidant issues worth consideration
}

\author{
F.J. Kelly, C. Dunster, I. Mudway
}

Air pollution and the elderly: oxidantlantioxidant issues worth consideration. F.J. Kelly, C. Dunster, I. Mudway. C) ERS Journals Ltd 2003.

ABSTRACT: The elderly are frequently classified as being particularly susceptible to air pollution. The basis of this increased sensitivity is not known but it is likely that it is linked to age-related impaired function of the lung. However, given this uncertainty and increased impact of air pollution of this section of the community there is a need to explore the mechanisms involved.

Gaseous air pollutants such as ozone and nitrogen dioxide, or many of the components adsorbed onto the surface of respirable particles, are either powerful oxidants or capable of generating free radicals. If unabated, oxidants can cause injury to the delicate cells that line the respiratory tract. Small molecular weight antioxidant defences present in respiratory tract lining fluid (RTLF) represent the first line of defence against a range of oxidants that enter the lung. The quantity and quality of the RTLF airways antioxidant network are, therefore, likely to be important determinants of the impact of the oxidant challenge on the underlying respiratory epithelium.

As yet, comprehensive information on the distribution and variability of respiratory tract lining fluid antioxidant defences is only available in young, mainly healthy volunteers. Studies undertaken in patients with a range of respiratory diseases suggest that marked changes in the distribution of respiratory tract lining fluid antioxidants can occur. Information is not currently available on the impact of ageing on the respiratory tract lining fluid antioxidant defence network. As several respiratory tract lining fluid antioxidants are of dietary origin, the elderly, who often have different dietary patterns to younger individuals, may have decreased availability of important antioxidants. Given these possibilities, a better understanding of respiratory tract lining fluid antioxidant defences in the aged lung is warranted.

Eur Respir J 2003; 21: Suppl. 40, 70s-75s.
Environmental Sciences Research Group, School of Health and Life Sciences, King's College London, London, UK.

Correspondence: F.J. Kelly

Environmental Sciences Research Group

School of Health and Life Sciences

Franklin-Wilkins Building

150 Stamford Street

King's College London

London, SE1 9NN

UK

Fax: 442078483891

E-mail: frank.kelly@kcl.ac.uk

Keywords: Air pollution

diet

elderly

oxidant and antioxidant status

respiratory tract lining fluid

Received and accepted: April 122002
Increasing age is accompanied by a progressive decline in lung function. This is measurable in spirometric terms as a reduction in forced expiratory volume in one second (FEV1) and forced vital capacity (FVC). Such changes are frequently accepted as the inevitable signs of the ageing process. The rate of loss of lung function is likely influenced by a number of external or environmental factors, including the quality of the individual's diet. As a consequence of the functional decline in their lungs, the elderly face the same challenges as younger people, albeit with a compromised respiratory system. Perhaps unsurprisingly, the elderly have for some time been considered to be an "at-risk group" from the impact of air pollution. Evidence supporting this notion was recently reported in the National Morbidity, Mortality and Air Pollution study [1]. It was found that, amongst the elderly, hospital admissions for cardiovascular problems increased $1 \%$ for each $10-\mu \mathrm{g}$ increase in particulates, while cardiopulmonary admissions rose $2 \%$.

It is currently unclear which, if any, of the age-related changes that occur in the lung predispose the elderly in this manner. Most elderly individuals do have reduced lung capacity and the imposition of a further reduction in lung function by air pollution may cause them to exceed a critical threshold. Likewise, as epidemiological studies indicate that air pollution is responsible for increased morbidity and mortality among the elderly with pre-existing cardiorespiratory conditions, it is relevant to question if, and how, such diseases further compromise an already susceptible lung. Clearly, increased basal inflammation exists in these patients and this would be further exacerbated following exposure to air pollution. To date, little work has been directed towards a mechanistic understanding of air pollution toxicity in the elderly. To fill this gap in knowledge, studies are required that address issues such as the lung function and inflammatory responses in aged subjects exposed to air pollution. In addition, it may also be informative to consider if, and how, diet influences lung function in the elderly and in particular, their respiratory tract lining fluid (RTLF) antioxidant defences.

\section{The lung and dietary antioxidants}

The lung acts as the primary portal of entry for oxygen and various oxidants to the body. It was therefore inevitable, following the realisation that the metabolism of oxygen gives rise to a number of highly reactive oxygen-derived free radicals [2], that the antioxidant defence systems of the lung would come under scrutiny. As several of the small molecular weight antioxidants are derived from the diet, it was also inevitable that links between diet and lung function would be sought.

Interest in dietary antioxidants first arose in the area of lung disease in the 1980 s, when retrospective observational 
Table 1.-Antioxidant nutrients: sources in fruit and vegetables

\begin{tabular}{lcc}
\hline Nutrient & Fruit & Vegetable \\
\hline Vitamin E & Apples & Asparagus \\
& Bananas & Broccoli \\
& Damsons & Carrots \\
& Blackcurrants & Peas \\
& & Spinach \\
Vitamin C & Tomatoes \\
& Blackcurrants & Brussel sprouts \\
& Cherries & Broccoli \\
& Kiwifruit & Cabbage \\
& Lemons & Cauliflower \\
& Melons & Potatoes \\
Beta-carotene & Strawberries & Spinach \\
& Apricots & Carrots \\
& Mangoes & Cabbage \\
& Melons & Lettuce \\
& Peaches & Parsley \\
\hline
\end{tabular}

studies suggested that individuals with low intakes of dietary antioxidants had decreased lung function. Studies by TOCKMAN et al. [3] and MorABIA et al. [4] indicated that dietary retinol levels are an important predictor of lung function. That is, individuals with higher retinol intakes tended to have better lung function. In 1990, SCHWARTZ and WEISS [5] reported the findings of the first National Health and Nutrition Examination Survey (NHANES I), which indicated that the dietary intake of vitamin $\mathrm{C}$ was positively and significantly associated with FEV1. In 1991, STRACHAN et al. [6] reported that smokers with high intakes of fresh fruit and fruit juice had a higher FEV1 than those with low intake of these foods (table 1). In 1993, in the Zutphen study [7], fruit intake was found to be inversely related to the incidence of chronic nonspecific lung disease. No association, however, was observed with the estimated intake of several antioxidants including $\beta$-carotene, vitamin $\mathrm{C}$ or selenium. In the monitoring project on risk factors and health in the Netherlands (MORGEN) study [8], a high intake of vitamin $\mathrm{C}$ and $\beta$-carotene, but not vitamin $\mathrm{E}$, was associated with a higher FEV1 and FVC than a low intake of these antioxidants, suggesting that they have a protective effect on lung function.

In addition to these epidemiological studies, there are a number of cross-sectional studies, in which associations have been made between blood concentrations of dietary antioxidants and lung function and/or respiratory symptoms. In 1986, TAYLOR et al. [9] reported that chronic obstructive pulmonary disease patients with an abnormal FEV1/ FVC ratio had decreased plasma antioxidant levels. In 1994, SCHWARTZ and WEISS [10] reported the findings of the NHANES II study, which suggested that both bronchitis and wheeze were negatively associated with serum vitamin $\mathrm{C}$ levels. In 1996, NESs et al. [11] reported that plasma vitamin C concentration correlates both with FEV1 and FVC in males, but not females. More recently, Mudway et al. [12] showed that FEV1 was not influenced by vitamin $\mathrm{C}$ supplementation in healthy, vitamin $\mathrm{C}$ replete, subjects.

Therefore, a growing body of evidence links the intake of vitamins and pro-vitamin $\beta$-carotene with lung function. Namely, a high intake of these dietary components is associated with higher FEV1 and FVC than low intakes, presumably as a result of improved antioxidant reserves to deal with the inevitable increases in reactive oxygen species. This scenario has been demonstrated in cystic fibrosis (CF) patients, who, because of decreased production of pancreatic juices, are unable to efficiently break down and absorb fat-soluble vitamin antioxidants, such as vitamin E and A [13, 14]. This problem, along with recurrent airway infections and increased neutrophil activity, mean that $\mathrm{CF}$ patients endure regular bouts of increased oxidative stress [15]. Moreover, as both lung function and antioxidants status decline with age in CF patients [16], it is possible that these two events are linked, although no long-term prospective studies have yet addressed this interesting possibility. Encouragingly, short-term intervention studies have shown that $\beta$-carotene supplementation reduces circulating markers of lipid peroxidation in $\mathrm{CF}$ patients $[17,18]$.

\section{The respiratory tract lining fluid antioxidant pool}

Work carried out over the last decade has helped identify that oxidative injury of the respiratory epithelium is minimised by the RTLF, a thin overlying layer of fluid, rich in antioxidant defences [19-21]. RTLF contains enzymes (e.g. superoxide dismutase, catalase), metal binding proteins (e.g. caeruloplasmin, transferrin) and an array of small molecules including glutathione (GSH), uric acid, cysteine, methionine, vitamin $C$ and vitamin $E$. Although it is appreciated that RTLF antioxidant pool sizes vary markedly in the normal population $[22,23]$ there is little appreciation as to the reason for this, or the mechanism(s) underlying these differences. Indeed there is a near complete lack of understanding of antioxidant kinetics across the blood/air barrier.

As a consequence of its high water solubility, vitamin $\mathrm{C}$ is widely distributed throughout the aqueous compartments of the body. As this antioxidant is probably freely diffusible it is likely that dietary intake plays an important role in determining RTLF vitamin C concentration. Studies in guinea pigs, which like humans are unable to synthesise vitamin $\mathrm{C}$, have shown that dietary deficiency of vitamin $\mathrm{C}$ quickly translates to decreased blood and RTLF vitamin C levels [24]. Differences in dietary intake may therefore explain, in part, the wide range of bronchoalveolar lavage (BAL) fluid vitamin $\mathrm{C}$ concentrations reported in humans [25]. In contrast the source of RTLF uric acid is not known. Several investigators including the present authors suspect that the majority of RTLF uric acid is derived from the circulation in much the same way as vitamin C. However, this cannot be the only source of uric acid in the upper airways, especially the nasal cavity, where RTLF has much higher uric acid concentrations than in the lower airways [23]. De novo synthesis of uric acid within the nasal epithelium seems an unlikely source, as the concentration and activity of xanthine dehydrogenase within the nasal epithelium is low [26]. It is likely that high concentrations of uric acid in the upper airways are achieved through active secretion of uric acid from cells lining the respiratory tract. RTLF is a two layer structure, comprising a lower aqueous Sol phase and an upper mucus, Gel phase. PEDEN et al. [26] have demonstrated that in the nasal cavity, RTLF Sol phase uric acid concentration is increased following cholinergic stimulation of the airways. Furthermore, they demonstrated that the increase in uric acid correlated positively with lactoferrin concentration, but not with albumin. As lactoferrin is predominately derived from mucosal gland secretions (Gel phase) this supports the contention that RTLF uric acid in the upper airways is derived, in part, from glandular secretions. Control of uric acid secretion in this compartment may therefore be closely related to mucus secretion.

Alveolar RTLF contains high concentrations $(400 \mu \mathrm{mol}$. $\mathrm{L}^{-1}$ ) of reduced GSH, which is $\sim 100$ times that present in plasma [27]. The source of this enormous GSH pool is not clear but passive diffusion is clearly not important. As stated 
above, passive diffusion cannot explain the high RTLF GSH concentrations, and cellular secretion is probably involved, coupled with poor re-absorption mechanisms. A number of cell types, including mononuclear phagocytes, lymphocytes and fibroblasts, are known to export GSH [28, 29]. Furthermore, the cell-surface enzyme responsible for the uptake of reduced GSH from the extracellular space, $\gamma$-glutamyl transpeptidase, is present at far lower concentrations in the lung than in other organs [30, 31]. In addition, RTLF is replenished relatively slowly, thus any GSH exported into RTLF is likely to remain there for prolonged periods and this may also contribute to the build-up of reduced $\mathrm{GSH}$ concentrations within this compartment [32].

\section{Respiratory tract lining fluid antioxidants and air pollution}

Both in vitro and in vivo experimental evidence exists to indicate that RTLF vitamin C, uric acid and GSH are consumed on exposure to ozone, nitrogen dioxide and particles $[33,34]$. These reactions are sacrificial in that both the pollutant (or reactive component on the particle surface) and antioxidants are consumed (fig. 1). Following such an event, it is obviously important that the lost antioxidants are replaced as rapidly as possible. How these events occur, and if they are regulated remains unclear. Although such information is crucial to understanding the ability of RTLF antioxidants to afford protection, such data is not available, even in healthy young volunteers.

It has been proposed that the composition and quantity of antioxidants within the RTLF compartment might represent a significant determinant of an individual's responsiveness to air pollutants such as ozone [19]. Whilst evidence suggests that good lung function is associated with diets rich in fruits and vegetables [35] there is little data linking basal pulmonary or blood antioxidant levels to individual responsiveness to oxidant gases under controlled conditions [36, 37]. It is however conceivable that boosting plasma antioxidant concentration of these antioxidants above the normal range could have a protective effect if this results in augmented RTLF antioxidant levels.

In support of this contention recent field studies have demonstrated that increased intakes of nutritional antioxidants can reduce the magnitude of lung function decrements in subjects exposed to high ozone doses both occupationally (shoe cleaners in Mexico City [38]) and recreationally (Dutch cyclists [39]). In these studies protection was observed after prolonged periods of supplementation $(75 \mathrm{mg}$ vitamin $\mathrm{E}$, $650 \mathrm{mg}$ vitamin C, $15 \mathrm{mg} \beta$-carotene, daily for 1.5 months in the Mexico City study; $100 \mathrm{mg}$ vitamin E, $500 \mathrm{mg}$ vitamin $\mathrm{C}$ daily for 15 weeks in the Dutch cyclist study) against average ozone backgrounds of 67.3 parts per billion (ppb) and $38.5 \mathrm{ppb}$ respectively. Notably, significant ozone episodes were only recorded in the Mexico City study, with numerous hourly episodes above $110 \mathrm{ppb}$.

Collaboration for these findings has been provided in a number of controlled chamber studies. CHATHAM et al. [40] reported protection against ozone-induced (300 ppb for $2 \mathrm{~h}$, with intermittent exercise) decrements in FVC in subjects supplemented with $800 \mathrm{IU}$ (528 mg) vitamin E for 14 days with a single $1 \mathrm{~g}$ vitamin $\mathrm{C}$ dose taken immediately before challenge. Notably, in this study, no protection was seen with vitamin $\mathrm{C}$ alone, and no protection against FEV1, forced midexpiratory flow (FEF25-75), and specific airway conductance decrements was observed. A recent (double-blinded) study examined a fuller range of response endpoints in two groups of 15-16 subjects exposed to $400 \mathrm{ppb}$ ozone for $2 \mathrm{~h}$ (minute ventilation, $20 \mathrm{~L} \cdot \mathrm{min}^{-1} \cdot \mathrm{m}^{-2}$ ) following placebo and vitamin supplementation (250 mg vitamin C, 50 IU (33 mg) vitamin $\mathrm{E}$, and a $12 \mathrm{oz}$ vegetable cocktail rich in carotenoids, daily for 14 days) [41]. In this study a small, yet significant blunting of the ozone-induced decrement in FEV1 $(p=0.05)$ was observed in the supplemented group with a similar trend $(\mathrm{p}=0.06)$ observed in the FVC response. No protection against ozoneinduced airway inflammation was reported. In this study

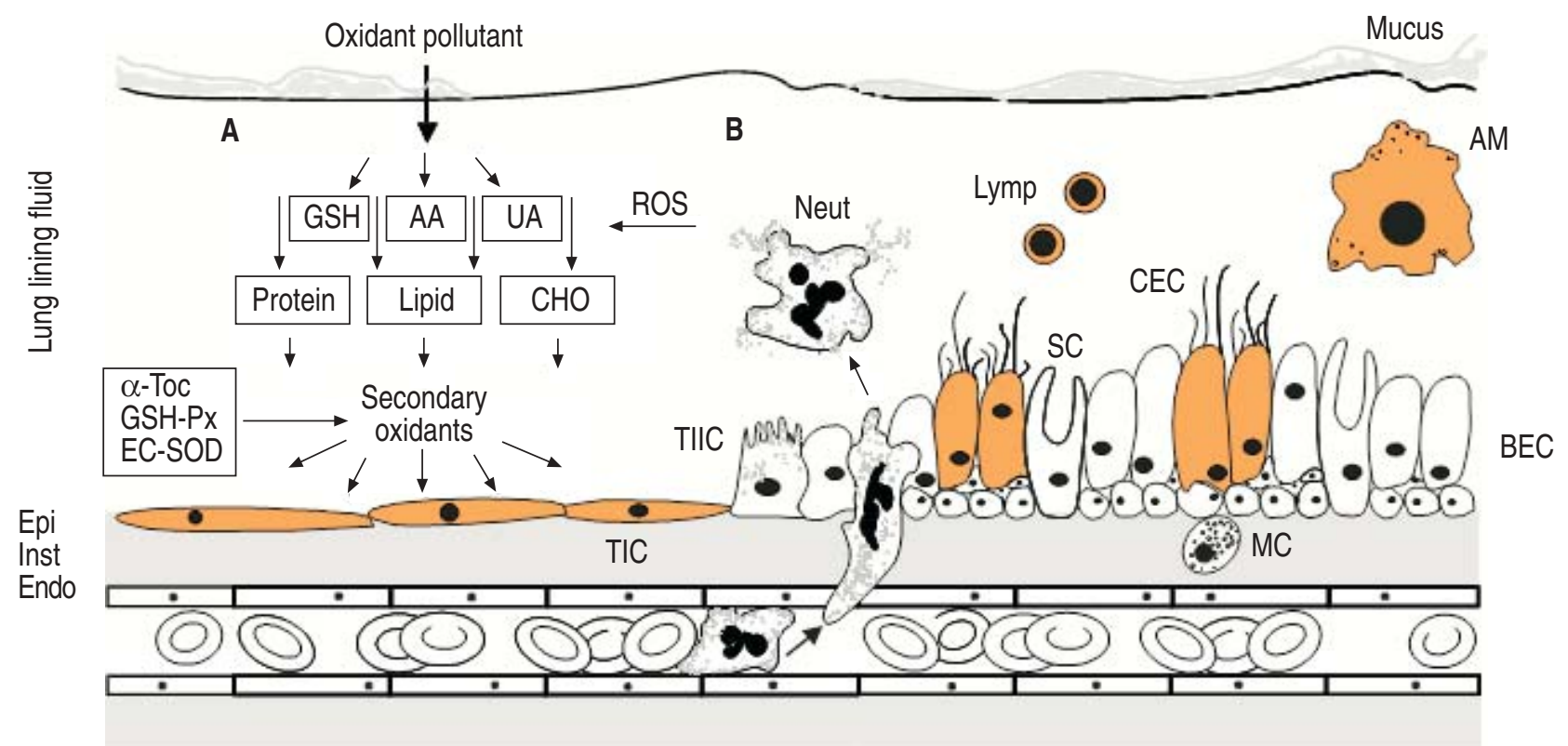

Fig. 1. - Proposed mechanism of oxidant pollution toxicity in the lung. A: biochemical events; B: cellular events. AA: ascorbate: UA: urate; GSH: glutathione (reduced); CHO: carbohydrate; ROS: reactive oxygen species; $\alpha$-Toc: $\alpha$-tocopherol; GSH-Px: glutathione peroxidase; EC-SOD: extracellular superoxide dismutase; epi: epithelial cell; inst: interstitium; endo: endothelial cell; neut: neutrophil; lymp: lymphocyte; AM: alveolar macrophage; MC: mast cell; TIC: type 1 epithelial cell; TIIC: type II epithelial cell; CEC: ciliated epithelial cell; BEC: bronchial epithelial cell; SC: secretory cell. 
subjects were initially placed on a restricted antioxidant diet for 7 days prior to entering the placebo, or vitamin predosing period, such that their initial vitamin $\mathrm{C}$, vitamin $\mathrm{E}$, and $\beta$-carotenoid concentrations were low: $34.2,13.3$ and $1.4 \mu \mathrm{mol} \cdot \mathrm{L}^{-1}$ (group means) respectively. In field studies, where protection had been observed, basal blood antioxidant levels, when measured, have been at the upper end of the normal range [38, 39, 42]. Whilst these studies examined responses in healthy subjects, a recent study by TRENGA et al. [43] addressed whether vitamin supplementation (500 mg vitamin C; $400 \mathrm{IU}$ (264 mg) vitamin E daily for 4 weeks) would protect asthmatics against ozone-induced (120 ppb for $45 \mathrm{~min}$, with mild exercise) lung function decrements and following subsequent provocation with sulphur dioxide $\left(\mathrm{SO}_{2}\right)$ (100 and $250 \mathrm{ppb}$ ). No difference between the pre- and post ozone lung function decrements (FVC, FEV1, FEF25-75 and peak expiratory flow) was observed between the supplement and placebo groups. Similarly, no difference was seen in the lung function decrement observed after $\mathrm{SO}_{2}$. Indeed, overall responses actually appeared to be larger in the vitaminreceiving group.

\section{Influence of disease on respiratory tract lining fluid antioxidants}

A range of lung diseases have been linked with oxidative stress (table 2). Epidemiological evidence suggests that those individuals with existing cardiorespiratory disease are particularly sensitive to the impact of air pollutants. Given that RTLF antioxidant defences play a crucial role in airways defence against pollution, it is important to consider the impact of disease on this antioxidant pool. To date, limited analysis of RTLF antioxidants have been conducted in cigarette smokers [27], idiopathic pulmonary fibrosis [44], asthma [45], adult respiratory distress syndrome [46], CF [47] and lung cancer [48]. Unfortunately, in the majority of these studies only one antioxidant was considered, and there is currently little appreciation of the overall antioxidant defence network in any of these diseases. The exception to this is asthma, in which detailed studies have now been undertaken [49, 50]. Interestingly, RTLF vitamin C and E concentrations were found to be low in patients with mild asthma, even though their blood levels were normal or increased (fig. 2). This important finding indicates that reliance on plasma measurements alone is not a sufficient indicator of airway antioxidant status, and highlights the fact that the relationship between plasma and RTLF antioxidant pools is unknown. The occurrence of low antioxidant vitamin

Table 2. - Free radical involvement in respiratory diseases

\begin{tabular}{ll}
\hline Free radicals & Respiratory disease \\
\hline Excessive production of & Asthma \\
superoxide, $\mathrm{H}_{2} \mathrm{O}_{2}$ and $\mathrm{HOCl}$ & Emphysema \\
by activated inflammatory cells & ARDS \\
& $\begin{array}{l}\text { Bronchopulmonary } \\
\text { dysplasia }\end{array}$ \\
& Cystic fibrosis \\
& Paraquat toxicity \\
Increased formation of reactive & Hyperoxia \\
oxygen species by drugs and toxins & Hypoxia \\
Abnormal oxidative substrate or & Cystic fibrosis \\
changes in oxygen concentration & Asthma \\
Inadequate antioxidant defences & ARDS \\
&
\end{tabular}

$\mathrm{H}_{2} \mathrm{O}_{2}$ : hydrogen peroxide; $\mathrm{HOCl}$ : hypochlorous acid; ARDS: adult respiratory distress syndrome. concentrations in the airways of asthmatic patients is particularly worrying, especially as the basis for this is unknown. Decreased consumption of fresh fruits and vegetables in recent decades [51] is unlikely to be the explanation, as blood levels of these were unaltered in these patients. More likely explanations include increased oxidative stress in the asthmatic lung and/or defective transfer of these antioxidants from the blood compartment.

\section{Influence of ageing on respiratory tract lining fluid antioxidant defences}

The majority of information regarding RTLF antioxidant defences is presently derived from bronchoscopy, or induced

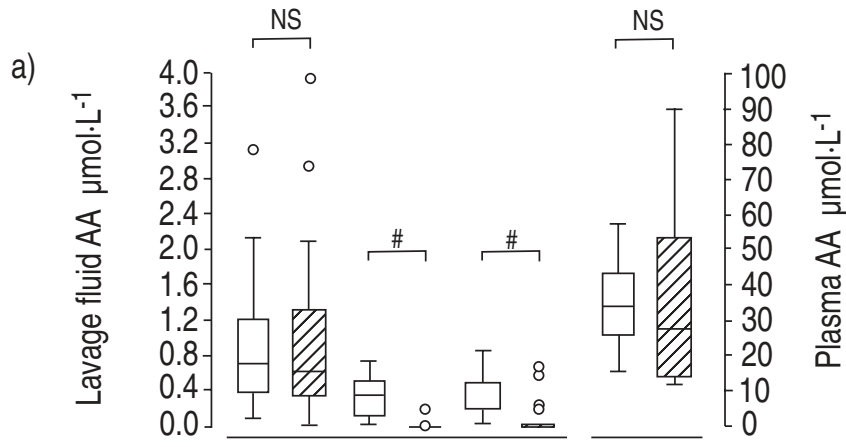

b)

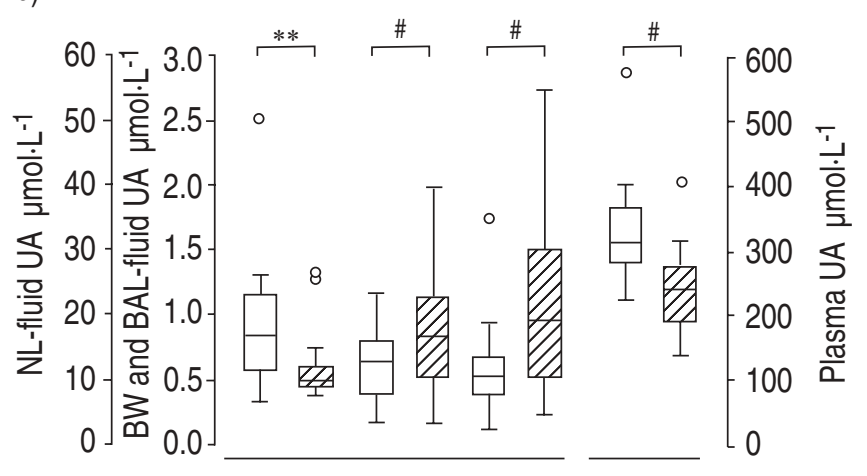

c)

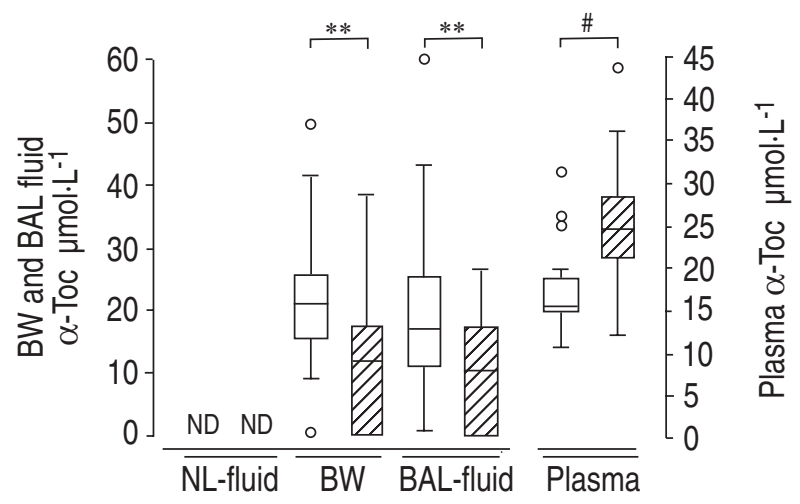

Fig. 2.-Comparison of the antioxidant concentrations, a) ascorbate (AA), b) urate (UA) and c) $\alpha$-tocopherol $(\alpha$-Toc)) in differential lavage fluid obtained from mild asthmatic $(\mathrm{n}=20 ; \mathbb{Z})$ and healthy control $(\mathrm{n}=20 ; \square)$ subjects. NL: nasal lavage; BW: bronchial wash; BAL: bronchoalveolar lavage; ND: not detected; NS: nonsignificant. Data represented as medians, with interquartile and full ranges $(\bigcirc$ : outliers). Plasma concentrations are illustrated for comparison. Based on data published in [49]. Comparison of concentrations was performed using Wilcoxon signed-rank test. ${ }^{* *}: \mathrm{p}<0.01$; $^{*}: \mathrm{p}<0.005$. 
sputum based studies, performed in relatively young, healthy volunteers, or young to middle-age patients with mild airways disease. As the antioxidant status of the blood compartment is altered in old age, it is feasible that this is also the case for RTLF antioxidants. If RTLF antioxidant defences are indeed compromised in older people, even in the absence of airways disease, this is likely to increase their sensitivity to air pollution. Therefore, a better understanding of this important host-defence mechanism is required in the elderly.

Support for the concept that RTLF antioxidant defences are altered in the elderly is evident from animal studies that indicate that GSH, the most abundant intracellular and extracellular nonprotein thiol, decreases with age [52]. The decrease in GSH probably occurs due to a decreased synthetic capacity, most likely owing to a decrease in g-glutamylcysteine synthetase activity. The mechanism underlying this age-related decline in the key enzyme in the GSH synthetic pathway is unknown. Studies of the airways in asymptomatic elderly humans suggest that inflammatory cell numbers are increased in comparison with younger volunteers [53]. This low-grade inflammation may influence RTLF antioxidant concentrations through increased free radical fluxes in the airways.

Ageing has also been associated with increased susceptibility to infection of the lung. BAL studies in clinically normal individuals of differing ages have revealed increasing cell numbers, interleukin- 6 concentrations and superoxide production in older subjects. These findings have been interpreted to indicate that low-grade inflammation does indeed exist in the lower respiratory tract of many asymptomatic, clinically normally healthy volunteers of advanced age. Given this, in the absence of compensatory antioxidant changes, it is feasible that RTLF antioxidant status is compromised in the elderly.

\section{Conclusions and recommended areas of study}

RTLF antioxidant defences act as the first, and probably the most important level of defence against inspired pollutants. The network of RTLF antioxidant defences is highly evolved and dynamic, in that deficiencies in certain aspects of the network can be offset by upregulation of others. For example, the presence of low RTLF vitamin C concentrations triggers increased levels of extracellular superoxide dismutase, urate and reduced GSH [36].

Any change in the RTLF antioxidant defence network in the elderly may explain their apparent increased susceptibility to air pollution. This may occur as a consequence of decreased vitamin intakes, increased basal oxidative stress (hence greater antioxidant demand), and probably most importantly, a decrease in their adaptive capacity.

At present, only comprehensive information on respiratory tract lining fluid antioxidant defences is available in healthy young volunteers. Therefore, studies are required to determine if, and in what manner, alterations to these defences occur in the elderly both with, and without, cardiopulmonary disease.

\section{References}

1. Samet JM, Zeger SL, Dominici F, et al. Health Effects Institute Report 94. National Morbidity, Mortality, and Air Pollution Study, Part II. Cambridge, MA, Heath Effects Institute, 2000.

2. Ward PA. Host-defense mechanisms responsible for lung injury. J All Clin Immunol 1986; 78: 373-378.

3. Tockman MS, Khoury MJ, Cohen BH. Milk drinking and possible protection of the respiratory epithelium. J Chron Dis 1986; 39: 207-209.

4. Morabia AA, Soreenson A, Kumanyika SK, Abbey H, Cohen BH, Chee E. Vitamin A, cigarette smoking, and airway obstruction. Am Rev Respir Dis 1989; 140: 1312-1316.

5. Schwartz J, Weiss ST. Dietary factors and their relation to respiratory symptoms. The second national health and Nutrition Examination Survey. Am J Epidemiol 1990; 132: 67-76.

6. Strachan DP, Cox BD, Erzinclioglu SW, Walters E, Whichelow MJ. Ventilatory function and winter fresh fruit consumption in a random sample of British adults. Thorax 1991; 46: 624-629.

7. Miedema I, Feskens EJM, Heederik D, Kromhout D. Dietary determinations of long term incidence of chronic non-specific lung disease. The Zutphen study. Am J Epidemiology 1993; 138: 37-45.

8. Grievink L, Smit HA, Ocké MC, Van't Veer P, Kromhout D. Dietary intake of antioxidant (pro)-vitamins, respiratory symptoms and pulmonary function: The MORGEN study. Thorax 1998; 53: 166-171.

9. Taylor JC, Madison R, Kosinka D. Is antioxidant deficiency related to chronic obstructive disease. Am Rev Respir Dis 1986; 134: 285-289.

10. Schwartz J, Weiss ST. Relationship between dietary vitamin $\mathrm{C}$ intake and pulmonary function in the First National Health and Nutrition Examination Survey (NHANES I). Am J Clin Nut 1994; 59: 110-114.

11. Ness AR, Khaw KT, Bingham S, Day NE. Vitamin C status and respiratory function. Eur J Clin Nutr 1996; 50: 573-579.

12. Mudway I, Blomberg A, Helleday R, Frew A, Sandstrom T, Kelly FJ. Supplementation with vitamin C does not influence lung function in healthy subjects. Eur Respir J 2000; 16: 116s.

13. Bye AME, Muller DPR, Wilson J, Wright VM, Mearns MB. Symptomatic vitamin E deficiency in cystic fibrosis. Arch Dis Child 1985; 60: 162-164.

14. Homnick DN, Cox JH, Deloof MJ, Ringer TV. Carotenoid levels in normal children and in children with cystic fibrosis. J Pediatr 1993; 122: 703-707.

15. Brown RK, Kelly FJ. Role of free radicals in the pathogenesis of cystic fibrosis. Thorax 1994; 49: 738-742.

16. Brown RK, Wyatt H, Price JF, Kelly FJ. Pulmonary dysfunction in cystic fibrosis is associated with oxidative stress. Eur Respir J 1996; 9: 334-339.

17. Winklhofer-Roob BM, Puhl H, Khoschsorur G, van't Hof MA, Esterbauer H, Shmerling DH. Enhanced resistance to oxidation low density lipoproteins and decreased lipid peroxide formation during $\beta$-carotene supplementation in cystic fibrosis. Free Rad Biol Med 1995; 18: 849-859.

18. Lepage G, Champagne J, Ronco N, et al. Supplementation with carotenoids corrects increased lipid peroxidation in children with cystic fibrosis. Am J Clin Nutr 1996; 64: 87-93.

19. Kelly FJ, Mudway I, Krishna TM, Holgate ST. The free radical basis of air pollution: focus on $\mathrm{O}_{3}$. Respir Med 1995; 89: 647-656.

20. Kelly FJ, Buhl R, Sandstrom T. Measurement of antioxidants, oxidants and oxidation products in bronchoalveolar lavage fluid. Eur Respir Rev 1999; 9: 93-98.

21. van der Vliet A, $\mathrm{O}^{\prime}$ Neill CA, Cross CE, et al. Determination of low-molecular-mass antioxidant concentrations in human respiratory tract lining fluids. Am J Physiol 1999; 276 (2 Pt 1): L289-296.

22. Housley DG, Mudway I, Kelly FJ, Eccles R, Richards RJ. Depletion of urate in human nasal lavage fluid following in vitro $\mathrm{O}_{3}$ exposure. Int $J$ Biochem 1995; 27: 1153-1159.

23. Peden DB, Robert H, Brown ME. Uric acid is a major antioxidant in human nasal airway secretions. Proc Natl Acad Sci USA 1990; 87: 7638-7642.

24. Dunster C, Kelly FJ. Dietary modulation of lung epithelial lining fluid vitamin C concentration. Respir Med 1994; 88 : 815.

25. Slade R, Crissman K, Norwood J, Hatch GE. Comparison 
of antioxidant substances in bronchioalveolar lavage cells and fluid from humans, guinea pigs, and rats. Exp Lung Res 1993; 19: 469-484.

26. Peden DB, Swiersz M, Ohkubo K, Hahn B, Emery B, Kaliner MA. Nasal secretion of the ozone scavenger uric acid. Am Rev Respir Dis 1993; 148: 455-461.

27. Cantin AM, North SL, Hubbard RC, Crystal RG. Normal alveolar epithelial lining fluid contains high levels of glutathione. J Appl Physiol 1987; 63: 152-157.

28. Meister A, Anderson ME. Glutathione. Annu Rev Biochem 1983; 52: 711-760.

29. Banni S, Tsukedu H. The export of glutathione from human diploid cells in culture. J Biol Chem 1979; 284: 3444-3450.

30. Griffith OW, Meister A. Glutathione: interorgan translocation, turnover and metabolism. Proc Natl Acad Sci USA 1979; 76: 5606-5610.

31. Joyce-Brady M, Takahashi Y, Oakes SM, et al. Synthesis and release of amaphipatic g-glutamyl transferase by pulmonary alveolar type II cells. J Biol Chem 1994; 269 : 14219-14226.

32. Smith LJ, Anderson JR, Shamsuddin M. Glutathione localization and distribution after intratracheal instillation. Am Rev Respir Dis 1992; 145: 153-159.

33. Zielinski H, Mudway IS, Berube KA, Murphy S, Richards R, Kelly FJ. Modelling the interactions of particles with epithelial lining fluid antioxidants. Am J Physiol 1999; 277: 719-726.

34. Mudway I, Krishna MT, Frew AJ, Holgate ST, Sandström T, Kelly FJ. Antioxidant consumption and repletion kinetics in nasal lavage fluid following exposure of healthy human subjects to ozone. Eur Respir J 1999; 13: 1429-1438.

35. Britton JR, Pavord ID, Richards KA, et al. Dietary antioxidant vitamin intake and lung function in the general population. Am J Respir Crit Care Med 1995; 151: 13831387.

36. Mudway IS, Stenfors N, Blomberg A, et al. Differences in basal airway antioxidant concentrations are not predictive of individual responsiveness to ozone: a comparison of healthy and mild asthmatic subjects. Free Radic Biol Med 2001; 31 : 962-974.

37. Blomberg A, Mudway IS, Nordenhall E, et al. Ozoneinduced lung function decrements do not correlate with early airway inflammatory or antioxidant responses. Eur Respir $J$ 1999; 13: 1418-1428.

38. Romieu I, Meneses F, Ramirez M, et al. Antioxidant supplementation and respiratory functions among workers exposed to high levels of ozone. Am J Respir Crit Care Med 1998; 158: 226-232.

39. Grievink 1, Zijlstra AG, Ke X, Brunekreef B. Double-blind intervention trial on modulation of ozone effects on pulmonary function by antioxidant supplements. Am J Epidemiol 1999; 149: 306-314.

40. Chatham MD, Eppler JH Jr, Sauder LR, Green D, Kulle TJ. Evaluation of the effects of vitamin $\mathrm{C}$ on ozone-induced bronchoconstriction in normal subjects. Ann NY Acad Sci 1987; 498: 269-279.

41. Samet JM, Hatch GE, Horstman D, et al. Effect of antioxidant supplementation on ozone-induced lung injury in human subjects. Am J Respir Crit Care Med 2001; 164: 819-825.

42. Grievink L, Jansen SM, Van't Veer P, Brunekreef B. Acute effects of ozone on pulmonary function of cyclists receiving antioxidant supplements. Occup Environ Med 1998; 55: 13-17.

43. Trenga CA, Koenig JQ, Williams PV. Dietary antioxidants and ozone-induced bronchial hyperresponsiveness in adults with asthma. Arch Environ Health 2001; 56: 242-249.

44. Cantin AM, Hubbard RC, Crystal RG. Glutathione deficiency in the epithelial lining fluid of the lower respiratory tract in idiopathic pulmonary fibrosis. Am Rev Respir Dis 1989; 139: 370-372.

45. Smith LJ, Houston M, Anderson J. Increased levels of glutathione in bronchoalveoloar lavage fluid from patients with asthma. Am Rev Respir Dis 1993; 147: 1461-1464.

46. Bunnel E, Pacht ER. Oxidised glutathione is increased in the alveolar fluid of patients with the adult respiratory distress syndrome. Am Rev Respir Dis 1993; 148: 1174-1178.

47. Roum JH, Buhl R, McElvaney NG, Borok Z, Crystal RG. Systemic glutathione deficiency in cystic fibrosis. $J$ Appl Physiol 1993; 75: 2419-2424.

48. Melloni B, Lefebvre MA, Bonnaud F, et al. Antioxidant activity in bronchoalveolar lavage fluid from patients with lung cancer. Am J Respir Crit Care Med 1996; 154: 17061711.

49. Kelly FJ, Mudway I, Blomberg A, Frew AJ, Sandström T. Altered lung antioxidant status in patients with mild asthma. Lancet 1999; 354: 482-483.

50. Comhair SAA, Bhathena PR, Dweik RA, Kavuru M, Erzurum SC. Rapid loss of superoxide dismutase activity during antigen-induced asthmatic response. Lancet 2000; 355: 624 .

51. Ministry of Agriculture. Household food consumption and Expenditure. Annual reports of the National Food Survey Committee. London, Her Majesty's Stationary Office, 1990; pp. 1961-1990.

52. Teramoto S, Fukuchi Y, Uejima Y, Teramoto K, Ito H, Orimo H. Age-related changes in the antioxidant screen of the distal lung in mice. Lung 1994; 172: 223-230.

53. Meyer KC, Ershler W, Rosenthal NS, Lu XG, Peterson K. Immune dysregulation in the aging human lung. Am J Respir Crit Care Med 1996; 153: 1072-1079. 